\title{
Nível de disclosure verde e a reputação corporativa ambiental das companhias brasileiras de capital aberto
}

\section{Level of green disclosure and the environmental corporate reputation of publicly traded brazilian companies}

\section{Paulo Sérgio Almeida-Santos}

Mestre em Ciências Contábeis pela Universidade Regional de Blumenau

Professor Assistente das Faculdades Integradas de Cacoal - UNESC

Endereço: Rua dos Esportes, 1038 - Bairro Incra - Caixa Postal 161

CEP: 76965864 - Cacoal/RO - Brasil

E-mail: paulosergio.almeidasantos@gmail.com

Telefone: (69) 3441-4503, Ramal - 239

\section{Alzenir José de Vargas}

Mestre em Ciências Contábeis pela Universidade Regional de Blumenau

Professor da Universidade Regional Integrada (URI) Campus de Frederico Westphalen

Endereço: Av. São Paulo 550, Bairro Aparecida

CEP: 98.400-000 - Frederico Westphalen/RS - Brasil

E-mail: ajvcontabilidade@gmail.com

Telefone: (55) 3744-8174

\section{Dalci Mendes Almeida}

Mestre em Ciências Contábeis pela Universidade Regional de Blumenau

Professora da Universidade do Sul de Santa Catarina (UNISUL)

Endereço: Avenida José Acácio Moreira, 787 - Bairro Dehon - Caixa Postal 370

CEP: 88704-000 - Tubarão/SC - Brasil

E-mail: dalci.almeida@unisul.br

Telefone: (48) 621-3000

\section{Carlos Eduardo Facin Lavarda}

Doutor em Contabilidade pela Universitat de Valencia, Espanha

Professor do Programa de Pós-graduação em Ciências Contábeis da Universidade Regional de Blumenau

Endereço: Rua Antônio da Veiga, 140, Sala D-202, Bairro Victor Konder

CEP: 89012-900 - Blumenau/SC - Brasil

E-mail: clavarda@furb.br

Telefone: (47) 3340-0938

Artigo recebido em 15/09/2010. Revisado por pares em 04/05/2012. Reformulado em 06/06/2012. Recomendado para publicação em 21/10/2012 por Sandra Rolim Ensslin (Editora Científica). Publicado em 14/12/2012. 


\title{
Resumo
}

O artigo identifica se a reputação corporativa ambiental explica o nível de disclosure verde das companhias brasileiras de capital aberto. Trata-se de uma pesquisa de abordagem quantitativa, do tipo descritiva e documental que investiga as 100 maiores companhias abertas brasileiras conforme o ranking da Revista Exame, edição julho/2010. Os resultados sugerem que as companhias listadas no Índice de Sustentabilidade (ISE) da BM\&FBovespa apresentam níveis mais acentuados de disclosure verde do que as empresas não listadas nesse mesmo índice. Conclui-se, desse modo, que as companhias, as quais possuem forte reputação corporativa ambiental, são as que demonstram maior nível de disclosure verde.

Palavras-chave: Disclosure verde. Reputação corporativa ambiental. Companhias abertas brasileiras.

\begin{abstract}
The article identifies if the environmental corporative reputation explains the level of green disclosure of publicly traded Brazilian companies. It is a research of quantitative approach, of descriptive and documental type that investigates the 100 largest Brazilian companies as ranking of Exame Magazine, July 2010 edition. The results suggest that the companies listed on the Sustainability Index (ISE) of BM\&FBovespa have the highest levels of green disclosure than the companies not listed on that index. We conclude, therefore, that the companies that have strong environmental corporate reputation are those that demonstrate the highest level of green disclosure.
\end{abstract}

Keywords: Green disclosure. Environmental corporate reputation. Publicly traded brazilian companies.

\section{Introdução}

A responsabilidade ambiental está se tornando cada vez mais necessária, passando a ser exigida pelos entes públicos, privados e pelo próprio cidadão comum. A sociedade está tomando consciência dessa necessidade. Assim, as empresas precisam evidenciar com mais transparência suas atividades ambientais, já que o investidor, o cliente, o fornecer, os órgãos legais, etc. exigem isso. Essa transparência, por exemplo, tem maior credibilidade quando ela advém de resultados obtidos ou alcançados mediante projetos sociais realizados pelas empresas (GONÇALVES et al., 2008).

Mudanças nas conjunturas social, econômica e política, na medida do possível, contribuem para que a divulgação das informações contábeis pelas organizações deva se adequar a elas, não tratando, portanto, as demonstrações contábeis especificamente de sua finalidade interna de gerenciamento; diversos são os potenciais usuários das informações divulgadas pelas empresas e muitos têm surgido devido ao desenvolvimento econômico da sociedade (SANTOS et al., 2010).

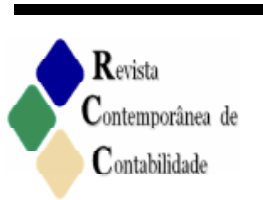


Entende-se que as empresas possuem obrigações para com a sociedade no que se refere à prestação de contas (accountability) de como utilizam os recursos naturais para produzirem bens e serviços, já que representam um dos principais agentes no processo de desenvolvimento econômico, sendo responsáveis pela intermediação entre o meio ambiente e o consumidor final (BRAGA; SALOTTI, 2008).

Com exceção de alguns setores regulados a maioria das empresas brasileiras não está obrigada a evidenciar informações ambientais, no entanto muitas já estão utilizando tal prática uma vez que, além da consciência socioambiental, acreditam que passarão a ser mais bem vistas pelos stakeholders, gerando para estes uma boa reputação no mercado. Segundo Gotsi e Wilson (2001, p. 28), a reputação corporativa consiste na avaliação completa realizada pelos stakeholders a respeito da companhia ao longo do tempo.

Para Rover, Murcia e Borba (2008, p. 2), "a divulgação de informações voluntárias também pode trazer benefícios às empresas, como, por exemplo, a redução do custo de capital, o aumento da liquidez das ações e a criação de uma imagem ambientalmente correta".

Diante disso, tem-se como hipótese que empresas com forte reputação corporativa ambiental tendem a apresentar maior nível de disclosure verde, ou seja, as empresas que possuem uma boa percepção da sociedade com relação ao seu comprometimento ambiental são empresas as que possuem maior evidenciação ambiental.

Com base nesses breves argumentos, formula-se a seguinte questão de pesquisa: A reputação corporativa ambiental explica o nível de disclosure verde das companhias brasileiras de capital aberto? Não obstante, o objetivo deste estudo consiste em identificar se a reputação corporativa ambiental explica o nível de disclosure verde das companhias brasileiras de capital aberto.

Segundo Silva et al., (2010, p. 165), "a evidenciação de informações ambientais atinge grandes proporções na atualidade, pois a humanidade preocupa-se cada vez mais com o desenvolvimento sustentável e a preservação ambiental". Depreende-se que, cada vez mais, torna-se evidente a necessidade de comprometimento, além da gestão pública, também das empresas privadas com a questão social e ambiental e a adequada divulgação das informações à sociedade, o que motiva a pesquisa.

Foram identificados estudos que relacionaram a reputação corporativa com o disclosure verde (TOMS, 2002; HASSELDINE et al., 2005; MICHELON, 2007; IDOWU; PAPASOLOMOU, 2007; CRUZ; LIMA, 2010) e estudos que trabalharam a divulgação ambiental (MURCIA et al., 2008; ROVER et al., 2008; ROVER et al., 2009). No entanto, não foram identificadas pesquisas que relacionaram se a reputação corporativa ambiental explica $o$ nível de disclosure verde, o que também justifica este estudo.

Gallon et al. (2007) salientam que a publicação na área ambiental, apesar de o número ainda ser incipiente de artigos, vem evoluindo muito. Observaram também que a categoria Gestão Ambiental se destacou com 50,54\% dos 186 artigos analisados, no entanto a categoria Evidenciação Ambiental foi a menos representativa dentre as quatro categorias examinadas (Contabilidade Ambiental, Evidenciação Ambiental, Gestão Ambiental e Sustentabilidade), o que também motiva o desenvolvimento desta pesquisa.

A pesquisa está estruturada em cinco seções iniciando com esta introdução. Em seguida, apresenta-se, na seção 2, a revisão de literatura; na seção 3, discorre-se sobre a metodologia da pesquisa; na seção 4, está a análise dos dados e os resultados, finalizando-se com as considerações finais. 


\section{Referencial Teórico}

\subsection{Disclosure Verde}

As empresas não estão se preocupando em divulgar somente o que está sendo exigido pelos órgãos correspondentes, estão evidenciado informações que permitem melhor relacionamento com os stakeholders, procurando principalmente manter os investidores já existentes e conquistar novos. Calixto et al. (2007, p. 87) destacam que "[...] a divulgação é vital para a tomada de melhores decisões possíveis e a divulgação oportuna de informação relevante tende a impedir a ocorrência de surpresas que poderiam alterar a percepção a respeito do futuro de uma empresa."

Para Melo et al. (2007, p. 32), "o verdadeiro intuito da disclosure é mostrar informações relevantes que possam transmitir segurança e confiança àqueles que pretendem investir em uma empresa".

As evidenciações são formas de divulgar o desempenho da empresa para os diversos usuários da informação. Hendriksen e Van Breda (1999, p. 512) mencionam que "no sentido mais amplo da palavra, divulgação simplesmente quer dizer veiculação da informação".

O disclosure poderá ser compulsório ou voluntário. Quando for compulsório, abrangerá as informações exigidas por lei, e quando for, voluntário envolverá informações não obrigatórias por lei. No entanto, o disclosure voluntário proporcionará um grau maior de transparência para as empresas no meio corporativo, podendo essas informações serem qualitativas ou quantitativas (LIMA et al., 2007).

O disclosure pode ser classificado em quatro categorias de informações: estratégicas, financeiras, ambientais e sociais (CRUZ; LIMA, 2010; MICHELON, 2007). As informações estratégicas englobam evidenciação como metas e objetivos da empresa, estratégias do negócio, principais produtos, ambiente competitivo, principais mercados, ou seja, informações relacionadas ao planejamento estratégico; as financeiras envolvem a evidenciação de informações econômico-financeiras; as ambientais evolvem a divulgação de informações sobre os impactos ambientais das atividades da empresa e suas políticas ambientais; as sociais envolvem a divulgação de informações relacionadas a aspectos sociais como, por exemplo, a responsabilidade do produto (CRUZ; LIMA, 2010).

As informações divulgadas deixam de ser somente financeiras e econômicas e passam a ser também sociais e ambientais. A evidenciação de informações ambientais, também conhecida como green reporting, diferencia-se da evidenciação focada nas informações de natureza econômico-financeira, no entanto sua divulgação é muito importante uma vez que os eventos ambientais podem impactar também na saúde financeira e na saúde econômica da empresa (por exemplo: multas e passivos ambientais, investimentos, etc.) (ROVER et al., 2008). Braga e Salotti (2008) corroboram com a ideia quando destacam que um bom ou um mau desempenho ambiental pode ter implicações em medidas de desempenho econômicofinanceiro ou, até mesmo, no valor da empresa, destacando que a informação contábil ambiental é relevante.

Berthelot et al. (2003) conceituam disclosure ambiental como um conjunto de informações que demonstram passado, presente e futuro do desempenho e da gestão ambiental da empresa, bem como os impactos financeiros das ações e decisões ambientais. Braga e Salotti (2008, p. 2) mencionam que o "termo disclosure ambiental pode ser entendido 
como a divulgação voluntária de informações ambientais feitas por empresas com o possível objetivo de atender a demanda informacional de algum usuário".

Segundo Nossa (2002, p. 86), "o disclosure ambiental pode ser feito de maneira obrigatória, quando exigido por leis e regulamentos, ou voluntariamente, quando a evidenciação de informações é feita por espontaneidade da empresa, mesmo que seja com base em diretrizes e orientações".

Diante do exposto, a divulgação ambiental são informações de caráter ambiental, divulgadas obrigatoriamente ou não pelas empresas em seus relatórios, procurando simplesmente atender à necessidade de algum usuário, ou até mesmo de intensificar sua reputação corporativa. Não obstante, é importante ressaltar que atualmente a divulgação de informações ambientais tem alcançado uma extensão considerável, tendo em vista a preocupação constante da sociedade com a preservação do meio ambiente, em que se almeja um desenvolvimento de caráter sustentável (SILVA et al., 2010). O estabelecimento de uma política voltada para o desenvolvimento sustentável "pode significar organizações, instituições e empresas atuando em suas regiões para satisfazerem as necessidades da população presente sem comprometer a capacidade das futuras gerações em satisfazerem suas próprias necessidades.” (VELLANI; RIBEIRO, 2009, p. 188).

\subsection{Reputação Corporativa}

A reputação corporativa são os atributos organizacionais, que refletem a forma pela qual os stakeholders veem a empresa como sendo uma boa organização (ROBERTS; DOWLING, 2002). Dowling (2001, apud Vance; Angelo, 2007, p. 95) argumenta que a reputação corporativa é um constructo baseado em valores decorrentes das percepções dos diferentes públicos (stakeholders) que se relacionam com a empresa. Para Toms (2002, p. 259), a "reputação é sem dúvida o mais importante dos ativos intangíveis".

Assim a reputação corporativa seria a percepção que clientes, investidores, fornecedores, empregados e todos que se relacionam com a empresa possuem sobre ela, sendo tal percepção construída ao longo do tempo por meio de suas ações. Para Cruz e Lima (2010, p. 87), o "[...] termo reputação corporativa está relacionado a uma percepção da sociedade (ou, de modo específico, das pessoas ou empresas que influenciam ou são influenciadas pelas ações da organização) sobre o comportamento da empresa ao longo do tempo".

Diversos são os fatores que moldam a imagem de uma empresa e consequentemente influenciam na sua reputação. Machado Filho (2002, p. 63) destaca que "[...] qualidade dos produtos que a empresa oferece os seus serviços agregados, as práticas comerciais com clientes, fornecedores, instituições de crédito, práticas internas de recursos humanos, capacidade de inovação tecnológica, entre outras".

A responsabilidade socioambiental que a empresa possui também é um forte fator que influencia na reputação corporativa e que pode influenciar a visão que os diversos stakeholders possuem sobre a empresa.

O relatório de sustentabilidade pode ser visto como um condutor de reputação no sentido de que comunica o desempenho ambiental e social de uma empresa aos seus stakeholders. Se uma empresa está se comportando como um "bom cidadão corporativo", em seguida, essas informações vão aumentar a reputação da organização (MICHELON, 2007, p.3). 
Parte das informações apresentadas no relatório de sustentabilidade, mencionado por Michelon (2007), no Brasil pode ser vista no Balanço Social de muitas empresas nacionais, todavia não segue, a rigor, as diretrizes do Global Reporting Initiative (GRI). De acordo com Mazzioni et al. (2007), informações referentes aos desempenhos econômico, financeiro, ambiental, social e de responsabilidade corporativa e pública podem ser divulgadas no Balanço Social. É válido mencionar que o relatório de sustentabilidade é o mais completo modelo de relatório em âmbito mundial de informações sobre os desempenhos social, ambiental e econômico das organizações, pois eles seguem as diretrizes do GRI, de acordo com o que diz o Instituto Ethos.

Tachizawa (2002) menciona que a responsabilidade social relaciona-se à do conceito da governança corporativa e à da gestão empresarial em situações cada vez mais complexas, destacando as questões ambientais e sociais consideradas importantes para a sobrevivência dos negócios. A responsabilidade social é convergente com estratégias de sustentabilidade de longo prazo, incluindo a preocupação dos efeitos das atividades desenvolvidas no contexto da comunidade onde a empresa está inserida (TACHIZAWA, 2002).

Tinoco e Kraemer (2004) destacam que a sustentabilidade passa pelo gerenciamento ecológico evidenciando que envolve a passagem do pensamento mecanicista para o pensamento sistêmico, ou seja, a percepção do mundo como máquina cede lugar à percepção do mundo como ser vivo.

Moura (2000) enfatiza que o crescimento econômico somente pode ser feito dentro da visão de "desenvolvimento sustentável", mantendo indefinidamente a disponibilidade de recursos financeiros usado pela geração atual e futura. A sustentabilidade envolve a ideia da manutenção dos estoques da natureza ou a garantia de sua reposição por processos naturais ou artificiais, olhando com cuidado a capacidade regenerativa da natureza.

A inclusão da proteção ambiental entre os objetivos da organização moderna amplia o conceito de administração, incluindo programas de reciclagem, medidas para poupar energia e outras inovações ecológicas. Essa mudança de paradigma precisa ser acompanhada por uma mudança de valores, passando da expansão para a conservação, da quantidade para a qualidade, da denominação para a parceria (TINOCO; KRAEMER, 2004).

Czesnat e Machado (2010) destacam que a divulgação das ações de Responsabilidade Socioambiental é uma forma eficaz de as empresas se legitimarem. A organização passa a ter legitimidade social a partir do momento em que suas crenças e valores alinham-se às crenças e aos valores que a sociedade entende como corretos. Segundo Daft (1999, p. 347), "a legitimidade é definida como a perspectiva de que as ações de uma organização são desejáveis, corretas e apropriadas dentro do sistema de normas, valores e crenças do ambiente". Consequentemente a legitimidade pode influenciar na reputação da empresa.

Quando as atividades das empresas correrem o risco de provocar danos ao ambiente, os gestores devem procurar restabelecer sua reputação evidenciando informações de natureza socioambiental, convencendo assim a sociedade de que suas atividades são aceitáveis (WILMSHURST; FROST, 2000).

A BM\&FBovespa (2010) menciona que "já há alguns anos iniciou-se uma tendência mundial dos investidores procurarem empresas socialmente responsáveis, sustentáveis e rentáveis para aplicar seus recursos". Nesse contexto, empresas geram valor ao acionista a longo prazo, pelo motivo de estarem mais preparadas para enfrentar possíveis riscos econômicos, sociais, bem como ambientais.

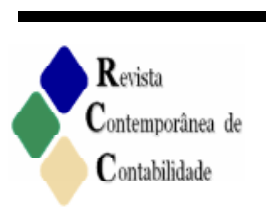




\subsection{Estudos Similares}

A seguir, apresentam-se estudos nacionais e internacionais que pesquisaram sobre reputação corporativa e sobre disclosure ambiental.

Toms (2002) estudou a relação entre a reputação ambiental e a divulgação ambiental de companhias do Reino Unido. Os resultados alcançados indicaram que a implementação, monitoramento e disclosure de políticas ambientais contribuem significativamente para a criação de reputação ambiental indicando que as empresas que possuem maior nível de informações ambientais possuem maior reputação.

Hasseldine et al. (2005) pesquisaram se a reputação corporativa ambiental tende a ser maior quando impactada pela quantidade ou pela qualidade de informações ambientais divulgadas em empresas britânicas mais admiradas pela comunidade em termos de Responsabilidade Ambiental. Os achados da pesquisa revelaram que a qualidade do disclosure ambiental, em vez da mera quantidade, é mais importante para a criação de reputação ambiental.

Michelon (2007) explorou a relação entre o disclosure da companhia e sua reputação, investigando os efeitos da reputação sobre o disclosure, examinando este último em quatro tipos de informações: estratégico, financeiro, ambiental e social. A pesquisa foi realizada com companhias norte-americanas e europeias. Os resultados evidenciaram que empresas com forte reputação corporativa divulgam uma quantia maior de informações financeira, estratégica, social e ambiental.

Idowu e Papasolomou (2007) identificaram as motivações que levam as empresas modernas britânicas a divulgarem em seus relatórios informações sobre sua responsabilidade social. Os resultados apontaram que as empresas possuem razões diferentes, porém, dentre outras, foi a reputação corporativa, elas acreditam que a divulgação é boa para os negócios, ou seja, para a sua reputação corporativa.

Murcia et al. (2008) analisaram a divulgação voluntária de informações ambientais nas demonstrações contábeis. Os achados da pesquisa apontaram que existe relação entre a informação ambiental apresentada de forma declarativa com uma notícia boa, divulgada no relatório da administração e que a informação monetária está mais relacionada com uma notícia neutra. Os resultados também apontaram que o fator tamanho e as variáveis, empresa de auditoria e participação no ISE são relevantes para a explicação do disclosure voluntário ambiental nas demonstrações contábeis.

Rover et al. (2008) examinaram as informações de caráter ambiental divulgadas voluntariamente pelas empresas brasileiras. Os resultados evidenciam que a categoria com maior número de sentenças ambientais é a de Políticas Ambientais, seguida pela Informações Financeiras Ambientais. Os autores concluíram também que a maioria das informações é declarativa, do tipo positiva corroborando com a Teoria do Disclosure Voluntário, em que as empresas não divulgam voluntariamente informações negativas.

Rover et al. (2009) pesquisaram os fatores que determinam a divulgação voluntária ambiental pelas empresas brasileiras potencialmente poluidoras. Os achados da pesquisa demonstraram que as variáveis, tamanho da empresa, sustentabilidade, empresa de auditoria e publicação do Relatório de Sustentabilidade (RS) são significativas para a explicação do disclosure voluntário ambiental.

Cruz e Lima (2010) analisaram se a reputação corporativa pode ser considerada um dos direcionadores do nível de disclosure voluntário das empresas de capital aberto do Brasil. 
Examinaram informações de natureza estratégica, econômico-financeira, ambiental e social. Constataram que a reputação corporativa possui uma associação positiva com a quantidade de evidenciação voluntária, indicando que as empresas que possuem forte reputação geram aos stakeholders mais disclosure voluntário.

\subsection{Construção da Hipótese}

Toms (2002), Hasseldine et al. (2005) afirmam que o disclosure das informações ambientais destinadas aos stakeholders é uma das formas de se aumentar a reputação corporativa ambiental. Nesse contexto, quanto mais informações voluntárias socioambientais a companhia divulgar ao mercado, maiores são as chances de ela elevar o seu grau de reputação corporativa, principalmente o de caráter ambiental.

Nessa mesma linha, Michelon (2007) afirma que a reputação corporativa ambiental é um dos fatores para que as empresas divulguem um número maior de informações de cunho socioambiental às partes interessadas. Assim, um dos diferenciais dessas empresas que apresentam níveis mais acentuados de divulgação ambiental é a sua participação em rankings de empresas comprometidas socialmente com o meio ambiente. Na Bolsa de Valores, elas podem estar destacadas nos índices diferenciados de empresas empenhadas com a sustentabilidade empresarial.

Em suma, espera-se que companhias, as quais têm forte reputação corporativaambiental, apresentem maior nível de disclosure verde ou divulgação de cunho socioambiental. Com base nessa premissa, a seguinte hipótese geral será testada no estudo:

\section{$H_{1}:$ Empresas brasileiras de capital aberto com forte reputação corporativa ambiental apresentam maior nível de disclosure verde.}

Portanto, para que a hipótese não possa ser rejeitada, espera-se uma relação estatisticamente positiva entre a reputação corporativa ambiental e o nível de disclosure verde das companhias brasileiras de capital aberto componentes da amostra.

\section{Metodologia da Pesquisa}

\subsection{Enquadramento da Pesquisa}

Quanto aos objetivos, a pesquisa é descritiva, pois os fatos serão analisados sem manipulação. Andrade (2002, p.124) menciona que "nesse tipo de pesquisa, os fatos são observados, registrados, analisados, classificados e interpretados, sem que o pesquisador interfira neles. Isto significa que os fenômenos do mundo físico e humano são estudados, mas não manipulados pelo pesquisador". Nesse contexto, buscará por meio deste trabalho descrever se a reputação corporativa ambiental explica o nível de evidenciação ambiental das empresas brasileira de capital aberto.

Quanto aos procedimentos, caracteriza-se como pesquisa documental. Segundo Marconi e Lakatos (2005, p. 176), "a característica da pesquisa documental é que a fonte de dados está restrita a documentos escritos ou não, chamados de fontes primárias. Estas podem ser feitas no momento em que os fatos ou fenômeno ocorrem, ou depois." Com isso, esta 
pesquisa constitui-se como documental, pois utilizou demonstrações financeiras padronizadas e suas respectivas notas explicativas como fonte de dados para análise, bem como os Relatórios Anuais (RA) e Relatórios de Sustentabilidades (RS) daquelas empresas que os disponibilizam em seus sítios.

No que se refere à abordagem do problema, este constitui-se como quantitativa, pois utilizará das técnicas estatísticas para fazer a análise dos dados coletados, a saber: estatísticas descritivas, teste binominal, correlação de Pearson, regressão linear múltipla, bem como testes auxiliares para validar o modelo proposto neste estudo. Nesse sentido, Raupp e Beuren $(2009$, p. 92) complementam que "a abordagem quantitativa caracteriza-se pelo emprego de instrumentos estatísticos, tanto na coleta quanto no tratamento dos dados".

\subsection{Definição da Amostra}

A amostra não probabilística e intencional desta pesquisa é composta pelas 100 maiores empresas brasileiras de capital aberto, tendo como proxy o valor de mercado de 2009, segundo o ranking da Revista Exame - Melhores \& Maiores, edição julho de 2010. Nessa edição, as seguintes empresas aparecem no ranking: Aços Villares, AES Eletropaulo, AES Tietê, All, Ambev, Amil, Ampla, Anhanguera Educacional, Aracruz, B2W, Banco do Brasil, Banrisul, BM\&FBovespa, BNB, BR Malls, Bradesco, Bradespar, Brasil Telecom, Braskem, Brasmotor, CCR, CEEE, CEEE-GT, Celesc, Celpe, Cemig, CESP, Coelba, Coelce, Comgás, Copasa, Copel, Cosan, Cosern, CPFL Energia, CSN, CTEEP, Cyrela Brazil Realty, Duke Energy, Duratex, EDP, Elektro, Eletrobrás, Embraer, Embrapar, Energisa, Fosfertil, Gafisa, Gerdau, Gol Linhas Aéreas, GVT Holding, Hypermarcas, Itaú, JBS, Klabin, Light Sesa, Localiza, Lojas Americanas, M. Dias Branco, Magnesita, Marfrig, MRV Engenharia, Multiplan, Natura, NET, Nossa Caixa, OGX Petróleo, Pão de Açúcar, PDG Realty, Perdigão, Petrobrás, Porto Seguro, Quattor, Rede, Redecard, Renner, Sabesp, Sadia, Santander, SLC Agrícola, Souza Cruz, Sul América Cia., Nac. Seguros, Suzano, TAM, Telefônica, Telemar, Tenaris Confab, Terna, Tim Participações, Tractebel, Energia, Ultrapar, Usiminas, Usina Costa Pinto, Vale, VCP, Vivo Participações, Vulcabrás, Weg, Whirlpool e Yara.

Destaca-se que, devido a quatro das 100 empresas não possuirem informações necessárias para análise de conteúdo, elas foram retiradas da amostra, sendo assim a amostra final da pesquisa foi composta por 96 empresas. Adicionalmente, segundo Murcia (2009), apesar de a seleção das 100 maiores empresas brasileiras ser algo intencional para se estudar, infere-se que essas companhias têm uma ampla representatividade dentre todas as companhias listadas na BM\&FBovespa.

\subsection{Variáveis e Modelo Econométrico do Estudo}

\subsubsection{Nivel de disclosure verde}

A variável que representa o nível de disclosure verde foi mensurada a partir da métrica construída por Murcia et al. (2008), conforme o Quadro 1. A métrica é divida em oito categorias e 36 subcategorias. Cada uma das 36 subcategorias é avaliada por uma sentença positiva: "1", quando a informação buscada da empresa é encontrada ou negativa; e "0", caso contrário. Dessa forma, ao final da análise é somado cada item encontrado, construindo-se, 
assim, o nível de disclosure verde (NDV), que é expresso percentualmente. O máximo que a empresa analisada poderá atingir é 100\% (36/36).

Quadro 1 - Métrica utilizada para medir o nível de disclosure verde

\begin{tabular}{|c|c|c|}
\hline Categorias & & Subcategorias - Divulgou: \\
\hline \multirow{6}{*}{ 1. Políticas Ambientais } & 01 & Declaração das políticas/práticas/ ações atuais e futuras? \\
\hline & 02 & Estabelecimento de metas e objetivos ambientais? \\
\hline & 03 & $\begin{array}{l}\text { Declaração indicando que a empresa está em obediência (compliance) } \\
\text { com as leis, licenças, normas e órgãos ambientais? }\end{array}$ \\
\hline & 04 & Parcerias ambientais? \\
\hline & 05 & Prêmios e participações em índices ambientais? \\
\hline & 06 & ISOs 9000 e/ou $14.000 ?$ \\
\hline \multirow{5}{*}{$\begin{array}{c}\text { 2. Sistemas de Gerenciamento } \\
\text { Ambiental }\end{array}$} & 07 & Auditoria ambiental? \\
\hline & 08 & Gestão ambiental? \\
\hline & 09 & Desperdícios/ Resíduos? \\
\hline & 10 & Processo de acondicionamento (Embalagem)? \\
\hline & 11 & Reciclagem? \\
\hline \multirow{6}{*}{$\begin{array}{l}\text { 3. Impactos dos produtos e } \\
\text { Processos no Meio Ambiente }\end{array}$} & 12 & Desenvolvimento de produtos ecológicos? \\
\hline & 13 & Impacto na área de terra utilizada? \\
\hline & 14 & Uso eficiente/ Reutilização de água? \\
\hline & 15 & Vazamentos e derramamentos? \\
\hline & 16 & Reparos aos danos ambientais? \\
\hline & 17 & Conservação e/ou utilização mais eficiente nas operações? \\
\hline \multirow{5}{*}{ 4. Energia } & 18 & Utilização de materiais desperdiçados na produção de energia? \\
\hline & 19 & Discussão sobre a preocupação com a possível falta de energia? \\
\hline & 20 & Desenvolvimento/ exploração de novas fontes de energia? \\
\hline & 21 & Investimentos ambientais \\
\hline & 22 & Custos / despesas ambientais? \\
\hline \multirow{4}{*}{$\begin{array}{l}\text { 5. Informações Financeiras } \\
\text { Ambientais }\end{array}$} & 23 & Passivos/Provisões ambientais? \\
\hline & 24 & Práticas contábeis de itens ambientais? \\
\hline & 25 & Seguro ambiental? \\
\hline & 26 & Ativos ambientais tangíveis e intangíveis? \\
\hline \multirow{2}{*}{$\begin{array}{l}\text { 6. Educação, Treinamento e } \\
\text { Pesquisas }\end{array}$} & 27 & Educação Ambiental (internamente e/ou comunidade)? \\
\hline & 28 & Pesquisas relacionadas ao meio ambiente? \\
\hline \multirow{4}{*}{ 7. Mercado de Créditos de Carbono } & 29 & Projetos de Mecanismos de Desenvolvimento Limpo (MDL)? \\
\hline & 30 & Créditos de carbono? \\
\hline & 31 & Emissão de Gases do Efeito Estufa (GEE)? \\
\hline & 32 & Certificados de Emissões Reduzidas (CER)? \\
\hline \multirow{4}{*}{ 8. Outras Informações Ambientais } & 33 & $\begin{array}{l}\text { Qualquer menção sobre sustentabilidade/ desenvolvimento } \\
\text { Sustentável? }\end{array}$ \\
\hline & 34 & Gerenciamento de florestas/ Reflorestamento? \\
\hline & 35 & Conservação da biodiversidade? \\
\hline & 36 & Stakeholders? \\
\hline
\end{tabular}

Fonte: Murcia et al. (2008).

O nível de disclosure também pode ser dado a partir da fórmula [1] com base nos itens de divulgação ambiental demonstrado no Quadro 1.

$$
N D V_{i} \underset{D A=1}{=} \sum \frac{D A_{j}}{D A}
$$

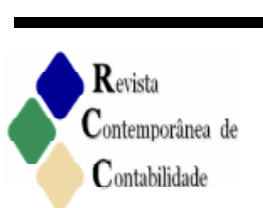


Onde:

NDV = Nível de disclosure verde da companhia $i$.

$\mathrm{DA}_{\mathrm{j}}=$ divulgação ambiental $\mathrm{j}$ em análise. Variável dicotômica (dummy) com valor 1 se a companhia divulgou e "0" caso contrário.

DA: Número máximo de item de divulgação ambiental (36)

\subsubsection{Reputação corporativa ambiental, Variáveis de controle e o Modelo econométrico}

Reputação corporativa ambiental. Neste estudo, é considerada a variável independente. Esta é mensurada utilizando-se uma variável dicotômica, onde é verificada a participação da companhia no Índice de Sustentabilidade (ISE) da BM\&FBovespa. Portanto, tem-se " 1 " em caso afirmativo e " 0 " caso contrário.

Tamanho. Trata-se de uma variável de controle medida pela proxy valor total de mercado da companhia em US\$ milhões segundo ranking da Revista Exame, edições Melhores e Maiores de 2010. Pesquisas anteriores asseguram que a divulgação da empresa, quer compulsória, quer voluntária, pode ser impactada pelo seu porte/tamanho. Nesse contexto, quanto maior é a empresa, maior é o seu nível de divulgação (ver: TOMS, 2002; HASSELDINE et al., 2005; MONTEIRO, 2007; MICHELON, 2007; MURCIA et al., 2008; CRUZ; LIMA, 2010).

Retorno sobre o Patrimônio Líquido (ROE). Trata-se de uma variável de controle medida pela razão do resultado do período pelo patrimônio líquido do início do período. Empresas que apresentam ótima rentabilidade sobre o seu patrimônio líquido também têm uma demanda maior por divulgação de informações voluntárias, abarcando-se as de caráter ambiental (TOMS, 2002; HASSELDINE et al., 2005; MONTEIRO, 2007; CRUZ; LIMA, 2010).

Endividamento. Trata-se de uma variável de controle medida pela razão do passivo circulante e não circulante pelo patrimônio líquido do período. Murcia et al., (2008) indicam que companhias que possuem maior capacidade de endividamento concorrem para apresentar maior nível de divulgação voluntária, sendo uma delas a evidenciação ambiental.

Auditoria. Trata-se de uma variável de controle medida por uma variável dicotômica, a qual avalia se a companhia é auditada por uma das grandes empresas multinacionais de auditoria, Pricewaterhouse Coopers, Deloitte Touche Tohmatsu, KPMG e Ernst \& Young, também chamadas de "big four". Portanto, se a companhia é auditada por uma "big four", atribui-se " 1 ", e "0" caso contrário. Companhias que apresentam uma boa qualidade de auditoria externa são mais suscetíveis a divulgarem um número maior de informações voluntárias (MURCIA et al., 2008).

Internacionalização. Trata-se de uma variável de controle medida por uma variável dicotômica que avalia se a companhia possui papéis negociáveis na Bolsa de Valores de Nova York (NYSE). Nesse caso, a companhias que possuem títulos na NYSE atribui-se "1", e "0" caso contrário. Pelo fato de o cenário internacional ser mais competitivo, informações de caráter voluntário têm grande valia para os investidores estrangeiros, ou seja, isso é um diferencial para a empresa ter continuidade nesse mercado. Portanto, companhias que estão inseridas no mercado internacional se veem obrigadas a ter um nível maior de divulgação, 
sendo um atributo importante as informações voluntárias (MURCIA et al., 2008; CRUZ; LIMA 2010).

Estimação do modelo. Com base nas variáveis levantadas, o modelo econométrico, que verifica a relação entre o nível de disclosure verde e a reputação corporativa ambiental das maiores companhias abertas brasileiras por valor de mercado são demonstradas conforme a equação [2]:

$$
N D V_{i t}=\beta_{0}+\beta_{1} R E P_{i t}+\beta_{2} T A M_{i t}+\beta_{3} R O E_{i t}+\beta_{4} E N D_{i t}+\beta_{5} A U D_{i t}+\beta_{6} I N T_{i t}+E R R O_{i t}
$$

Onde:

$\beta_{0}=$ Constante do modelo.

$\beta_{1} \ldots \beta_{6}=$ Coeficientes estimados no modelo de cada variável.

NDV = Nível de disclosure verde da companhia $i$ no ano $t$.

REP $=$ Reputação corporativa ambiental da companhia $i$ no ano $t$.

TAM = tamanho da companhia $i$ no ano $t$.

ROE $=$ Rentabilidade sobre o Patrimônio Líquido da companhia $i$ no ano $t$.

END $=$ Grau de endividamento da companhia $i$ no ano $t$.

AUD $=$ Qualidade da auditoria da companhia $i$ no ano .

INT $=$ Grau de internacionalização da companhia $i$ no ano $t$.

$\mathrm{ERRO}=$ Erro estimado pela regressão.

\subsection{Procedimento para Coleta e Tratamento dos Dados}

O procedimento da coleta dos dados ocorreu por meio da análise de conteúdo realizada nas Demonstrações Financeiras Padronizadas (DFPs), nos Relatórios Anuais e de Sustentabilidade das companhias componentes da amostra. Esses documentos foram obtidos nos sítios eletrônicos das companhias, bem como no site da BM\&FBovespa, tendo o ano de 2008 como referência.

O Tratamento dos dados dar-se-á por meio da estatística descritiva, teste binominal, análise de correlação e regressão linear múltipla.

Estatistica descritiva. Utilizada para descrever os valores médios, mínimos e máximos, além do desvio padrão do nível de disclosure ambiental das companhias.

Teste binominal. Utilizado para testar a ocorrência de uma das duas realizações de uma variável dicotômica, bem como para testar a proporção dessa ocorrência no total de ocorrências registradas.

Análise de correlação. Utilizada para verificar em que nível as variáveis da pesquisa estão correlacionadas, se positiva ou negativamente de forma significativa.

Regressão linear múltipla. Utilizada para testar a hipótese geral do estudo, a qual analisa a relação positiva entre a reputação corporativa ambiental e o nível de disclosure verde. 


\subsection{Limitações}

No desenvolvimento deste estudo, algumas limitações podem ser ponderadas, por exemplo, no que diz respeito à amostra investigada e ao período que ele compreende. Foram observadas as 100 maiores companhias brasileiras de capital aberto por valor de mercado no ano de 2009, segundo a $37^{\mathrm{a}}$ edição das Melhores \& Maiores (2010) da Revista Exame, Editora Abril. Portanto, generalizações para grupo de companhias que não estão nesse ranking não são possíveis. Concomitantemente a isso, destaca-se o ano de 2010 por este ser o ano da mais atual edição da M\&M. Assim sendo, a pesquisa se restringe apenas ao ano em destaque, destarte a interpretação dos seus achados e possíveis generalizações para períodos anteriores ou posteriores não poderem ser consideradas.

\section{Resultados}

\subsection{Estatística Descritiva}

A Tabela 1 apresenta a estatística descritiva referente à variável nível disclosure verde (NDV), cuja definição operacional encontra-se na seção da metodologia deste estudo. As empresas que compõem a amostra evidenciaram em média $27,78 \%$ do total de informações ambientais a serem divulgadas. Por sua vez, o desvio-padrão desse valor de 16,56\% indica que a quantidade de empresas que apresentam menor nível de divulgação ambiental têm uma representação maior na amostra. Destaca-se ainda que os percentuais mínimos e máximos foram $0,00 \%$ e $80,56 \%$, respectivamente.

Tabela 1 - Estatística descritiva da variável nível disclosure verde

\begin{tabular}{|c|c|c|c|c|c|c|}
\hline \multirow{2}{*}{ Média } & \multirow{2}{*}{ Desvio-Padrão } & \multirow{2}{*}{ Máximo } & \multirow{2}{*}{ Mínimo } & \multicolumn{3}{|c|}{ Percentil } \\
\hline & & & & 25 & 50 & 75 \\
\hline $27,78 \%$ & $16,56 \%$ & $80,56 \%$ & $0,00 \%$ & $16,67 \%$ & $27,78 \%$ & $38,20 \%$ \\
\hline
\end{tabular}

Fonte: Dados da pesquisa.

Com base na análise dos quartis, as empresas apresentaram uma forte concentração percentual entre $16,67 \%$ e $38,20 \%$, indicando que $50 \%$ das empresas estariam nessa escala. Os $50 \%$ dessas empresas têm uma média de divulgação ambiental próxima a $30 \%$ numa escala de $0 \%$ a $100 \%$.

\subsection{Teste Binominal}

Pelo motivo da variável de reputação corporativa ambiental ser dicotômica (sim/não), a ideia é verificar se existem diferenças estatisticamente positivas entre a proporção das empresas brasileiras de capital aberto que estão listadas e não listadas no Índice de Sustentabilidade Empresarial (ISE) da BM\&FBovespa. Por conseguinte, o objetivo do teste consiste em verificar se tal parâmetro utilizado para medir a reputação corporativa ambiental das companhias investigadas pode estar associado com a quantidade de informações ambientais fornecidas pelos grupos de empresas. 
Tabela 2 - Distribuição percentual das empresas listadas e não listadas no índice de sustentabilidade empresarial - ISE da BM\&FBovespa

\begin{tabular}{lcc}
\hline & Grupo $^{1}$ & Grupo $^{2}$ \\
\cline { 2 - 3 } Listadas no ISE & Sim & Não \\
$N^{o}$ de Empresas & 23 & 73 \\
Média do Nível de Disclosure Verde & $35,51 \%$ & $27,74 \%$ \\
\hline
\end{tabular}

Fonte: Dados da pesquisa.

Conforme a Tabela 2, o Grupo ${ }^{1}$ é composto pelas empresas que estão listadas no ISE, composto por 23 empresas que atingiram uma média de evidenciação de informações ambientais de $35,51 \%$. O Grupo ${ }^{2}$ é composto pelas companhias que não estão listadas no ISE, representado por 73 empresas. Esse grupo atingiu uma média de evidenciação ambiental de $27,74 \%$.

Não obstante, para corroborar se o grupo de empresas que estão listadas no ISE da BM\&FBovespa ( $p)$ é igual ao grupo de empresas que não estão listadas no ISE $(q)$, utilizou-se Teste Binominal para verificar tal equiparação. Desse modo, as seguintes hipóteses são testadas:

$$
\begin{aligned}
& \boldsymbol{H}_{0}: p=q \\
& \boldsymbol{H}_{1}: p \neq q
\end{aligned}
$$

Portanto, para que a hipótese $H_{0}$ seja rejeitada, é esperado que a probabilidade seja menor que 0.05 ( $p$-value <0.05), caso ocorra o inverso ( $p$-value $>0.05)$, aceita-se $H_{0}$.

Tabela 3 - Teste binominal para os grupos de empresas listadas e não listadas no ISE da BM\&Fbovespa

\begin{tabular}{lllllll}
\hline & & Categoria & $\mathrm{N}$ & Probabilidade Obs. & Probabilidade Test. & $\begin{array}{c}P- \\
\text { value }\end{array}$ \\
\hline Reputação Corporativa & & & & & \\
Ambiental & $\mathrm{Grupo}_{1}$ & Não Listadas & 73 & .76 & .50 & $.000^{*}$ \\
& $\mathrm{Grupo}_{2}$ & Listadas & 23 & .24 & & \\
& Total & & 96 & 1 & & \\
\hline
\end{tabular}

Fonte: Dados da pesquisa.

Como demonstrado na Tabela 3 , pode-se concluir que para uma probabilidade de erro de 5\% ( $p$-value <0.05) existe evidência estatística suficiente para se rejeitar a hipótese de que existem igualdades estatisticamente significavas entre as proporções de empresas listadas no ISE e empresas não listadas no ISE. Dessa forma, rejeita-se $H_{0}$ e consequentemente se aceita $H_{l}$, visto que a probabilidade foi menor que $5 \%$ (p-value. < 0.05 ). Portanto, as empresas listadas no ISE tendem de certa forma evidenciar maior quantidade de informações ambientais do que aquelas empresas que não compõem a carteira do índice.

No entanto, para sustentar a hipótese central do estudo no qual as empresas com forte reputação corporativa ambiental são aquelas que apresentam maior nível de disclosure ambiental, será aplicado o método de regressão linear múltipla cujo objetivo esperado no 
modelo é que a variável de reputação corporativa ambiental (REP) seja estatisticamente positiva dentro do modelo proposto.

\subsection{Correlações das Variáveis}

Antes de se fazer a análise da regressão linear múltipla, optou-se por verificar a correlação das variáveis da pesquisa pela aplicação da Correlação de Pearson. É importante ressaltar que foi aplicado o teste não paramétrico de Kolmogorov-Smirnov para verificar sua normalidade por meio do teste verificou-se uma distribuição normal das variáveis a um nível de $5 \%$ ( $p$-value $<0.05)$.

Tabela 4 - Matriz de correlação das variáveis $(N=96)$

\begin{tabular}{rrrrrrrr}
\hline & \multicolumn{1}{c}{ NDV } & \multicolumn{1}{c}{ REP } & \multicolumn{1}{c}{ TAM } & REN & END & AUD & INT \\
\hline NDV & 1. & & & & & & \\
REP & $.201^{*}$ & 1 & & & & & \\
TAM & $.501^{* *}$ & $.221^{*}$ & 1 & & & & \\
REN & .003 & .068 & $.224^{*}$ & 1 & & & \\
END & .052 & .060 & $.203^{*}$ & -.032 & 1 & & \\
AUD & -.073 & .108 & .132 & -.099 & .030 & 1 & \\
INT & $.373^{* *}$ & $.230^{*}$ & $.484^{* *}$ & $-.205^{*}$ & .002 & .047 & 1 \\
\hline
\end{tabular}

$*$ p-value $<0.05 ; * *$-value $<0.01$.

Fonte: Dados da pesquisa.

A matriz de correlação apresenta três variáveis independentes que possuem correlações estatisticamente significativas com a variável dependente, nível de disclosure verde, a saber: reputação corporativa ambiental $(r=0,20 ; p$-value $<0.05)$, tamanho $(r=0,50$; $p$-value $<0.01)$ e internacionalização $(r=0,373$; $p$-value $<0.01)$. Todavia, quanto às variáveis de rentabilidade $(r=0,003 ; p$-value $>0.10)$, endividamento $(r=0,052 ; p$-value $>0.10)$, e auditoria $(r=-0,073 ; p$-value $>0.10)$, não houve correlação destas diante da variável de disclosure verde. Estudos de Toms (2002), Hasseldine et al. (2005) e Michelon (2007) também encontraram correlações estatisticamente significativas entre a variável de evidenciação ambiental e reputação corporativa ambiental. Desse modo, a boa reputação corporativa que as empresas tendem a apresentar à sociedade no intuito de atrair novos investidores, por exemplo, poderá ser um motivo para evidenciarem mais informações de cunho socioambiental (MICHELON, 2007).

É importante ressaltar que o nível de correlação de $1 \%$ (p-value $<0.01$ ) entre a variável Tamanho e nível de disclosure ambiental foi o mesmo nível de correlação nos estudos de Michelon (2007), bem como no de Monteiro (2007), corroborando assim a ideia de que o fator tamanho pode ser um indicativo, que as empresas de grande podem evidenciar quantidades maiores de informações ambientais do que empresas de menor porte.

Quanto à correlação apresentada pela variável internacionalização diante da variável de disclosure verde indica que o motivo de algumas empresas brasileiras possuírem títulos negociados no mercado internacional, elas se comprometem a apresentar maior transparência, bem como melhores práticas de disclosure, conforme defendem Murcia e Santos (2009).

\subsection{Regressão Linear Múltipla}


Na Tabela 5 é demonstrada a estimação do modelo de regressão linear múltipla. Os resultados apresentados são válidos, de acordo com o apresentado pelo teste $\mathrm{F}$, pois, como o (Sig.) é menor que $5 \%$ ( $p$-value $<0.05)$, é rejeitada a hipótese de que o $\mathrm{R}^{2}$ é igual a zero $\left(\mathrm{H}_{0}=\right.$ $0)$, portanto, ao menos uma das variáveis independentes exerce influência sobre a variável dependente NDV, logo o modelo é significativo. O poder explicativo do modelo foi de $37 \%$, conforme o coeficiente de correlação ao quadrado ou $\mathrm{R}^{2}$ ajustado $(0,368)$. Ressalta-se também a ausência de heterocedasticidade, pelo motivo da estatística do F, apontar para uma relação significativa entre a variável dependente e as variáveis independentes.

Tabela 5 - Estimação do modelo de regressão

\begin{tabular}{ccccc}
\hline Variáveis & Coeficiente & T & Sig. & VIF \\
\hline (Constant) & -.255 & -2.471 & .015 & \\
REP & .047 & 1.494 & $.013^{*}$ & 1.078 \\
TAM & .074 & 5.022 & $.000^{* *}$ & 1.679 \\
REN & -.032 & -1.155 & .251 & 1.283 \\
END & -.001 & -.388 & -.699 & 1.074 \\
AUD & -.050 & -1.525 & .131 & 1.047 \\
$I N T$ & 0.047 & 1.303 & .196 & 1.587 \\
\hline
\end{tabular}

$* p<0.05 ; * * p<0.01$.

Estatística $\mathrm{F}=9,937(p$-value $<0.05)$

$\mathrm{R} 2=0,409 ; \mathrm{R} 2$ ajustado $=0,368$

Durbin-Watson $=1,962$

$$
\mathrm{A}-\mathrm{b}
$$

Fonte: Dados da pesquisa.

Pelo modelo nota-se também que a variável Reputação foi positiva estatisticamente conforme o esperado. No entanto, quanto às variáveis de controle do modelo, apenas a variável Tamanho foi considerada estatisticamente significante ao nível de 5\% ( $p$-value < 0.05), confirmam estudos anteriores que utilizaram a mesma variável, a saber: Toms (2002), Hasseldine et al. (2005), Michelon (2007), Murcia et al. (2008) e Cruz e Lima (2010). A partir de tal resultado apresentado pelo modelo, aceita-se a hipótese testada nesta pesquisa.

Faz se necessário ressaltar que o motivo pelo qual o tamanho da empresa seja significativo no modelo corrobora a ideia da "political cost hipothesis" (WATTZ; ZIMMERMAN, 1986, apud Murcia; Santos, 2009), na qual as empresas de grande porte possuem pressão política devido à sua reputação e ao seu impacto na economia. Murcia e Santos (2009) complementam que devido ao fato de as empresas grandes possuírem um departamento de contabilidade maior, com mais recursos para preparar e divulgar suas demonstrações contábeis, por consequência, isso também influência o nível de evidenciação da empresa.

No entanto, por meio dos resultados apresentados pelo modelo estatístico, também se verificou que as demais variáveis de controle não apresentaram significâncias estatisticamente positivas.

Adicionalmente, por meio do Teste de Durbin-Watson, verifica-se que o valor apresentado na Tabela $5(1,962)$ indica a ausência de autocorrelação serial, atendendo dessa forma o pressuposto da regressão. Ressalta-se que para esse teste valores estatísticos próximos a "2" atendem ao pressuposto da regressão. Também se destaca a ausência de multicolinariedade entre as variáveis do modelo, visto que o indicador VIF de ambas é menor do que 10.

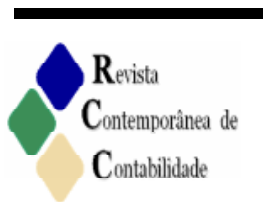




\section{Considerações Finais}

Este artigo analisou se a reputação corporativa ambiental explica o nível de disclosure verde das companhias brasileiras de capital aberto. Os resultados empíricos encontrados suportam a existência dessa influência. Primeiro, verificou-se que as companhias, que estão listadas no Índice de Sustentabilidade Empresarial da BM\&FBovespa, apresentam uma média de divulgação de informações socioambientais maior do que aquelas companhias que não estão listadas no ISE, o que justifica inclusive a diferença estatística entre esses dois grupos de empresas. Esse resultado coaduna-se com a literatura sobre o assunto, quando afirma que empresas com forte reputação corporativa ambiental concorrem para divulgar maior nível de informações socioambientais. Em segundo lugar, percebeu-se que a reputação corporativa ambiental possui relação positiva com o nível de disclosure verde, sinalizando que a hipótese geral do estudo não pode ser rejeitada.

Portanto, este estudo está em consonância com a literatura anterior, ao afirmar que empresas com forte reputação social corporativa também apresentam maior nível de disclosure verde ou divulgações de informações socioambientais. Nessa perspectiva, a evidência observada neste artigo nas companhias abertas brasileiras é coerente com as evidências observadas em outros países/regiões, tais como: Grã-Bretanha (TOMS, 2002); Reino Unido (HASSELDINE et al., 2005); e Estados Unidos e Europa (MICHELON, 2007). Nessa direção, as companhias abertas brasileiras investigadas que apresentam maior nível de disclosure verde possuem um diferencial das demais companhias, sendo ele, por exemplo, as suas participações no Índice de Sustentabilidade Empresarial da Bolsa de Valores de São Paulo. Doravante, as companhias que têm preocupação com o meio ambiente são altamente valorizadas no mercado, fazendo com que elas se sobressaiam ante as demais empresas, principalmente no que diz respeito à qualidade das suas informações, pois elas buscam apresentar aos seus investidores além das informações compulsórias, dando prioridade também às informações de caráter voluntário, entre elas a informações socioambientais, chamadas de disclosure verde.

Assim, contribuímos para a literatura em dois pontos: primeiro, no que tange a divulgações de informações voluntárias; em segundo, no que diz respeito à relação entre a reputação corporativa ambiental e o disclosure verde, assunto este ainda recente na literatura. Isso vem ao encontro de que a reputação corporativa ambiental é um fator institucional que aumenta o nível de disclosure verde das companhias brasileiras listadas na Bolsa de Valores local.

Adicionalmente, foi verificado que o fator Tamanho influencia na divulgação de informações ambientais, isto é, empresas de grande porte apresentam níveis maiores de informações socioambientais em relação às empresas de menor porte. No entanto, não se pode afirmar o mesmo quanto aos fatores rentabilidade, endividamento, auditoria $\mathrm{e}$ internacionalização.

Trabalhos futuros poderão contribuir com pesquisas sobre a relação entre a reputação corporativa ambiental e o disclosure verde, pois, como foi verificado, ainda não se têm uma gama de trabalhos que tratem especificamente do assunto. Como sugestão de pesquisa, podese verificar essa relação de modo inverso ao proposto neste estudo, isto é, identificar se, quando uma empresa apresenta maior nível de disclosure verde, maior é a probabilidade de ela possuir uma boa reputação corporativa ambiental. 


\section{Referências}

ANDRADE. M. M. Como preparar trabalhos para cursos de pós-graduação: noções práticas. 5 ed. São Paulo: Atlas, 2002.

BERTHELOT, S.; CORMIER, D.; MAGNAN, M. Environmental disclosure research: review and synthesis. Journal of Accounting Literature, v. 22. p. 1-44, 2003.

BRAGA, J. P.; SALOTTI, B. M. Relação entre nível de disclosure ambiental e características corporativas de empresas no Brasil. In: CONGRESSO USP DE INICIAÇÃO CIENTÍFICA EM CONTABILIDADE, 5., 2008, São Paulo/SP. Anais... São Paulo: USP, 2008.

CALIXTO, L.; BARBOSA, R. R.; LIMA, M. B. Disseminação de informações ambientais voluntárias: relatórios contábeis versus internet. Revista Contabilidade e Finanças USP. São Paulo. Edição 30 Anos de Doutorado, p. 84-95, 2007.

CRUZ, C. V. O. A.; LIMA, G. A. S. F. Reputação corporativa e nível de disclosure das empresas de capital aberto no Brasil. Revista Universo Contábil. Blumenau, n. 1, p. 85-101, jan./mar., 2010.

CZESNAT, A. F. O.; MACHADO, D. D-P. N. Legitimação na evidenciação de informações socioambientais nas empresas de telecomunicações listadas na BOVESPA. In: CONGRESSO DA ASSOCIAÇÃO NACIONAL DOS PROGRAMAS DE PÓS-GRADUAÇÃO EM CIÊNCIAS CONTÁBEIS, 4., 2008, Natal/RN. Anais... Natal: ANPCONT, 2010. CD-ROM.

DAFT, R. L. Teoria e projeto das organizações. 6. ed. Rio de Janeiro: LTC, 1999.

EXAME. Melhores \& Maiores: as 1000 empresas do Brasil, edição n. 37. São Paulo: Editora Abril, 2010.

GALlON, A. V.; SOUZA, F. C.; ROVER, S.; BELLEN, H. M. V. Produção científica e perspectivas teóricas da área ambiental: um levantamento a partir de artigos publicados em congressos e periódicos nacionais na área de contabilidade e administração. In: CONGRESSO USP DE CONTABILIDADE E CONTROLADORIA, 7, 2007, São Paulo/SP. Anais... São Paulo: USP: 2007. CD-ROM.

GONÇALVES, R. S.; WEFFORT, E. F. J.; PELEIAS, I. R.; GONÇALVES, A. O. Social Disclosure das empresas brasileiras listadas na NYSE e na BOVESPA: sua relação com os níveis de governança corporativa. Revista Contemporânea de Contabilidade, n. 9, p. 71-94, jan./jun. 2008.

GOTSI, M.; WILSON, A. M. Corporate reputation: seeking a definition. Corporate Communications, v. 6, p. 24-30, 2001.

HASSELDINE, J.; SALAMA, A. I.; TOMS, J. S. Quantity versus quality: the impact of environmental disclosures on the reputations of UK Plcs. The British Accounting Review. v. 37, p. 231-248, 2005.

HENDRIKSEN, E. S.; VAN BREDA, M. F. Teoria da contabilidade. São Paulo: Atlas, 1999.

IDOWU, S. O.; PAPASOLOMOU, I. Are the corporate social responsibility matters based on good intentions or false pretences? An empirical study of the motivations behind the issuing of CSR reports by UK companies. Corporate Governance. v. 7, p. 136-147, 2007. 
LIMA, G. A. S. F.; LIMA, I. S.; FÁVERO, L. P. L.; GALDI, F. C. Influência do disclosure voluntário no custo de capital de terceiros. In: CONGRESSO USP CONTROLADORIA E CONTABILIDADE, 7., 2007, São Paulo/SP. Anais... São Paulo, USP, USP, 2007. CD-ROM.

MACHADO FILHO, C. A. P. Responsabilidade social corporativa e a criação de valor para as organizações: um estudo multicasos. São Paulo, 2002. 204 p. Tese (Doutorado em Administração). Faculdade de Economia, Administração e Contabilidade da Universidade de. São Paulo.

MARCONI, M. A.; LAKATOS, E. M. Fundamentos de metodologia científica. 6 ed. São Paulo: Atlas, 2005.

MAZZIONI, S.; TINOCO, J. E. P.; OLIVEIRA, A. B. S. Informações evidenciadas no Balanço Social: as percepções dos gestores de forma comparada à literatura. Revista Contemporânea de Contabilidade, n. 7, p. 61-80, jan./jun., 2007.

MELO, F. M. A.; PONTE, V. M. R.; OLIVEIRA, M. C. Análise das práticas de evidenciação de informações avançadas e não-obrigatórias nas demonstrações contábeis das empresas brasileiras. Revista de Contabilidade e Organizações, n. 1, p. 30-42, set./dez. 2007.

MICHELON, G. Sustainability disclosure and reputation: a comparative study. Università Degli Studi di Padova. Working Paper. Sept./2007.

MONTEIRO, S. M. S. Factores explicativos do grau de divulgação ambiental em grandes empresas a operar em Portugal: análise multivariada. Conocimiento, innovación y emprendedores: camino al futuro, 2007. p. $1005-1023$. Disponível em: $<$ http://dialnet.unirioja.es/servlet/articulo?codigo=2233287>. Acesso em: 23 de ago. 2010.

MOURA, L. A. A. Economia Ambiental: Gestão de Custos e Investimentos. São Paulo: Juarez de Oliveira, 2000.

MURCIA, F. D-R. Fatores determinantes do nível de disclosure voluntário de companhias abertas no Brasil. 2009, 182 f. Tese (Doutorado em Controladoria e Contabilidade) - Universidade de São Paulo: São Paulo, 2009.

MURCIA, F. D-R.; SANTOS, A. Fatores determinantes de nível de disclosure voluntário das companhias abertas no Brasil. Revista de Educação e Pesquisa em Contabilidade. n. 2, p. 72-95, maio/ago. 2009.

MURCIA, F. D-R.; ROVER, S.; LIMA, I.; FÁVERO, L. P. L.; LIMA, G. A. S. F. 'Disclosure verde' nas demonstrações contábeis: características da informação ambiental e possíveis explicações para a divulgação voluntária. Revista UnB Contábil, Brasília, n.1-2, p. 260-278, jan./dez. 2008.

NOSSA, V. Disclosure ambiental: uma análise do conteúdo dos relatórios ambientais de empresas do setor de papel e celulose em nível internacional. São Paulo, 2002. 246 f. Tese (Doutorado em Controladoria e Contabilidade) - Faculdade de Economia, Administração e Contabilidade, Universidade de São Paulo.

RAUPP, F. M.; BEUREN, I. M. Metodologia da Pesquisa Aplicável às Ciências Sociais. In: BEUREN, I. M.: (Org.). Como Elaborar Trabalhos Monográficos em Contabilidade: teoria e prática. 3 ed. São Paulo: Atlas, 2009. 
ROBERTS, P. W.; DOWLING, G. R. Corporate reputation and sustained superior financial performance. Strategic Management Journal, v. 23, p. 1077-1093, 2002.

ROVER, S.; MURCIA, F. D-R; BORBA; J. A. Divulgação de informações ambientais nas demonstrações contábeis: um estudo exploratório sobre o disclosure das empresas brasileiras pertencentes a setores de alto impacto ambiental. In: CONGRESSO DA ASSOCIAÇÃO NACIONAL DOS PROGRAMAS DE PÓS-GRADUAÇÃO EM CIÊNCIAS CONTÁBEIS, 2., 2008, Salvador/BA. Anais... Salvador: ANPCONT, 2008. CD-ROM.

ROVER, S.; TAMAZZIA, E. C.; MURCIA, F. D-R. Explicações para a divulgação voluntária ambiental no Brasil utilizando análise de regressão em painel. In: CONGRESSO DA ASSOCIAÇÃO NACIONAL DOS PROGRAMAS DE PÓS-GRADUAÇÃO EM CIÊNCIAS CONTÁBEIS - IAAER. 3., 2009, São Paulo/SP. Anais... São Paulo: ANPCONT- IAAER, 2009. CD-ROM.

SANTOS, N. N. F.; FLORES, E. S.; GUIMARÃES, I. P.; SLOMSKI, V. G.; SILVA, A. F. Nível de evidenciação obtido na divulgação das notas explicativas de instrumentos financeiros derivativos segundo a deliberação CVM n. 550/08. Revista Contemporânea de Contabilidade, n. 13, p. 175-196, jan./jun. 2010.

SILVA, J. O.; CUNHA, P. R.; KLANN, R. C.; SCARPIN, J. E. Evidenciação dos Custos Ambientais nas Empresas que Compõem o Índice de Sustentabilidade Empresarial (ISE). Revista de Contemporânea de Contabilidade, n. 14, p. 159-182, jul./dez. 2010.

TACHIZAWA, T. Gestão Ambiental e Responsabilidade Social Corporativa. São Paulo: Atlas, 2002.

TINOCO, J. E. P.; KRAEMER, M. E. P. Contabilidade e Gestão Ambiental. São Paulo: Atlas, 2004.

TOMS, J. S. Firm resources, quality signals and the determinants of corporate environmental reputation; some UK evidence. British Accounting Review, Kidlington, v. 34, p. 257-282, 2002.

VANCE, P. S; ÂNGELO, C. F. Reputação corporativa. Revista de Gestão USP. São Paulo, n. 4, p. 93-108, dez. 2007.

VELLANI, C. L.; RIBEIRO, M. S. Sustentabilidade e contabilidade. Revista Contemporânea de Contabilidade, n. 11, p- 187-206, jan./jun. 2009.

WILMSHURST, T. D.; FROST, G. R. Corporate environmental reporting a test of legitimacy theory. Accounting Auditing and Accountability Journal, v. 13, p.10-26, 2000. 